\title{
Effects of soil-vegetation-atmosphere interaction on the stability of a clay slope: a case study
}

\author{
Giuseppe Pedone ${ }^{1, a}$, Aikaterini Tsiampousi ${ }^{2}$, Federica Cotecchia ${ }^{3}$ and Lidija Zdravkovic ${ }^{2}$ \\ ${ }^{1}$ Geotechnical Consulting Group, London, UK \\ (formerly Technical University of Bari, Department of Civil, Environmental, Territorial, Building and Chemical Engineering, Bari, Italy) \\ ${ }^{2}$ Imperial College London, Department of Civil \& Environmental Engineering, London, UK \\ ${ }^{3}$ Technical University of Bari, Department of Civil, Environmental, Territorial, Building and Chemical Engineering, Bari, Italy
}

\begin{abstract}
Deep and slow landslide processes are frequently observed in clay slopes located along the Southern Apennines (Italy). A case study representative of these processes, named Pisciolo case study, is discussed in the paper. The geo-hydro-mechanical characteristics of the materials involved in the instability phenomena are initially discussed. Pluviometric, piezometric, inclinometric and GPS monitoring data are subsequently presented, suggesting that rainfall infiltration constitutes the main factor inducing slope movements. The connection between formation of landslide bodies and slope-atmosphere interaction has been demonstrated through a hydro-mechanical finite element analysis, whose results are finally reported in the work. This analysis has been conducted employing a constitutive model that is capable of simulating both saturated and unsaturated soil behaviour, as well as a boundary condition able to simulate the effects of the soil-vegetation-atmosphere interaction.
\end{abstract}

\section{Introduction}

Deep and slow landslides are recurrently observed in clay slopes in the Southern Apennines (Italy) [1,2]. Despite the fact that the landslide movements are slow, the displacement rates show seasonal variations, with trends similar to those characterising the pore pressures. Hence, the landslide activity appears to be influenced by the hydraulic regime of the slope, which in turn depends on the soil-vegetation-atmosphere interaction.

The correlation between the landslide movements, the pore pressure changes and the slope-atmosphere interaction was assessed using numerical analyses $[3,4]$. In particular, fully coupled hydro-mechanical analyses of the Pisciolo case study [5], which is representative of the above mentioned processes, were performed. The present paper briefly introduces the case study and reports some results of the numerical analysis.

\section{Pisciolo case study}

The Pisciolo slope has been intensively studied in the last decade, as severe damage has been caused on existing infrastructures from landslide bodies (Fig. 1) [5]. In particular, the high landslide risk associated with a $2 \mathrm{~m}$ diameter pipeline has prompted a wide geotechnical investigation campaign, aimed at identifying the landslide causes and designing appropriate stabilisation measures.
The geo-morphological setting of the slope (Fig. 1) has been defined from stereoscopic analyses of aerial photos and monitoring data interpretation. It is characterised by the presence of slow to extremely slow roto-translational landslides [6], whose shear bands vary from intermediate to deep (up to $60 \mathrm{~m}$ of depth) [7]. The deepest shear bands occur in the southern portion of the unstable area (Fig. 1) and appear to be characterised by a retrogressive activity [5].

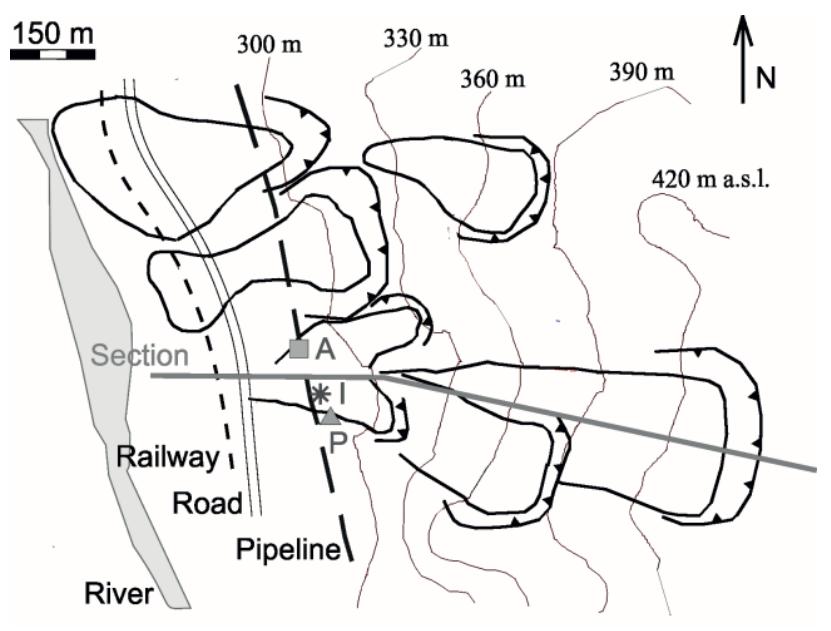

Figure 1. Geo-morphological map of the Pisciolo slope reporting the active landslide bodies (bold continuous lines), the location of inclinometer (I), piezometer (P), GPS antenna (A) cited in the text (Fig. 2) and the modelled section (Fig. 4) [5].

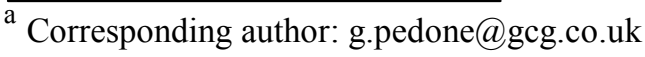


Failure mainly involves the fissured clay part of a turbiditic formation, which is a transition between the Numidian Flysch and the Red Flysch. The transition soils have a clay fraction of $40-60 \%$ and are characterised by high activity ( 0.85 on average), low mechanical strength ( $\mathrm{c}^{\prime}=0 \mathrm{kPa}$ and $\varphi^{\prime}=20.7^{\circ}$ for $\mathrm{p}^{\prime}<300 \mathrm{kPa}$ ) and high saturated permeability $\left(\mathrm{k}_{\text {in situ }}>10^{-9} \mathrm{~m} / \mathrm{s}\right)$ [5, 8]. Such hydro-mechanical behaviour is primarily due to the fissured meso-structure of the clay, which impoverishes the mechanical strength properties and increases the hydraulic conductivity with respect to that of the same material when unfissured [1-4, 8-11]. Fissuring also affects the unsaturated soil behaviour [4, 5, 8], as observed when subjecting the Pisciolo clay to dryingwetting cycles, during which the suctions have been measured by means of the filter paper technique [12] and the Imperial College high capacity tensiometers [13].

The movements of the landslide bodies have been monitored by means of both inclinometers and GPS sensors (Fig. 2), that recorded the maximum velocities at the end of winter. The landslide activity appears to be connected to the hydraulic regime of the slope, because the highest displacement rates are observed concurrently with the maximum pore pressures (Fig. 2). In turn, the hydraulic regime seems to be strictly connected to the pluviometric regime of the area, as observed by analysing the 6-month cumulative rainfall (Fig. 2). The latter clearly shows the seasonal character of the pluviometric events in the South of Italy, where rainfalls are more frequent from late autumn to mid spring, while they reduce drastically during late spring and summer [5].

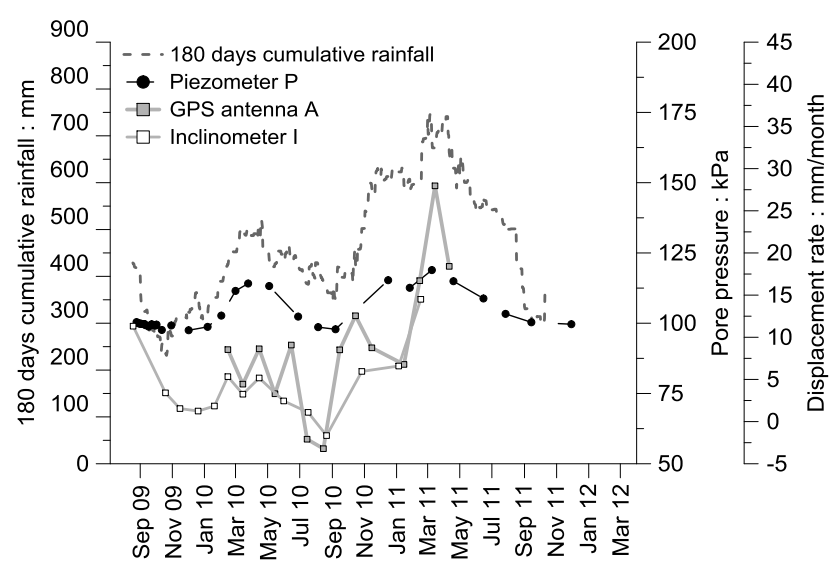

Figure 2. 180 days cumulative rainfall measured at a weather station located in Melfi (Italy), pore pressures measured at $15 \mathrm{~m}$ depth (piezometer P in Fig. 1), displacement rates measured at $18 \mathrm{~m}$ depth (inclinometer I in Fig. 1) and at the ground level (GPS antenna $\mathrm{A}$ in Fig. 1) [4, 5].

The monitoring data (Fig. 2) suggest that the slopeatmosphere interaction represents the main triggering factor of the instabilities. Rainfall infiltration appears to induce an increase in pore pressure that generates a reduction of the available shear strengths, which in turn produces an acceleration of the landslide movements.

\section{Numerical modelling}

The effect of slope-atmosphere interaction on the stability of the Pisciolo slope was investigated by means of a $2 \mathrm{D}$ fully coupled hydro-mechanical analysis [3, 4], conducted with the finite element code ICFEP [14]. The code has fully developed capabilities with reference to unsaturated soil behaviour [15].

The numerical simulation was conducted using the constitutive model proposed by Tsiampousi et al. [16], which was developed within the framework introduced by Alonso et al. [17]. On the wet side of critical state, the yield and plastic potential functions implemented in the model correspond to those reported by Lagioia et al. [18]. On the dry side, in order to avoid overestimation of shear strength, a Hvorlsev surface is employed, whose shape is defined by means of two parameters, named $n_{\mathrm{HV}}$ and $\alpha_{\mathrm{HV}}$ [16]. The former is a fitting parameter, while the latter represents the inclination of the Hvorslev surface at critical state (Fig. 3).

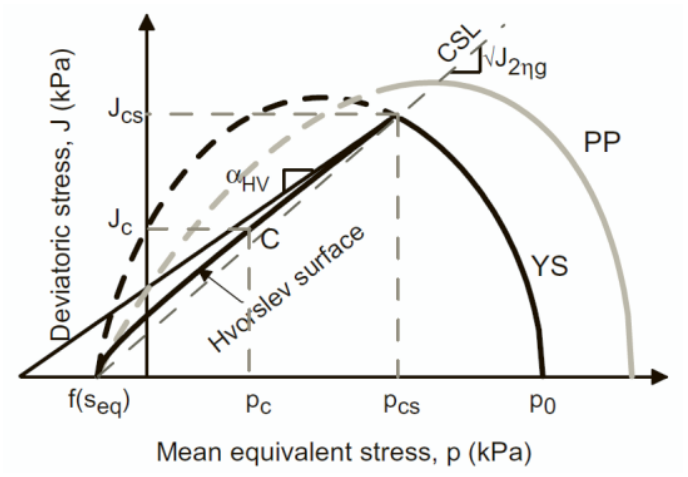

Figure 3. Yield surface (YS) and plastic potential (PP) for the constitutive model proposed by Tsiampousi et al. [16].

Additionally, a loading-collapse curve and a suction increase yield surface are employed, similar to Alonso et al. [17]. Desaturation occurs when suction exceeds the air entry value, which has been considered equal to $1000 \mathrm{kPa}$ in the present work. Under unsaturated conditions, apparent cohesion changes as a function of suction and degree of saturation [16]. Finally, the elastic coefficient of compressibility due to changes in suction, $\kappa_{\mathrm{s}}$, is dependent on the degree of saturation, $S_{r}$, according to the expression proposed by Tsiampousi et al. [19]:

$$
\kappa_{\mathrm{s}}=\chi\left(\mathrm{S}_{\mathrm{r}}\right)^{\omega}
$$

where $\chi$ and $\omega$ are fitting parameters.

The calibration of the constitutive model, with particular reference to the saturated soil behaviour, was performed through the simulation of oedometer and triaxial tests [3-5]. The oedometer tests allowed to identify the compressibility behaviour of the Pisciolo clay (well represented by the parameters $\lambda=0.0914$ and $\kappa=0.0365$ ), while the triaxial tests allowed to define the inclination of the critical state line (assumed as $\mathrm{M}=0.689$ ), as well as the parameters that describe the shape of the yield function (equal to $\mathrm{n}_{\mathrm{HV}}=0.45$ and $\alpha_{\mathrm{HV}}=0.3$ ). 
With reference to the unsaturated soil behaviour, the model was employed in a simplified form, as only unconfined drying tests were available for the calibration process $[4,5,8]$. In particular, a linear loading collapse curve has been considered and all the suction-induced deformations have been assumed elastic, albeit nonlinear, as the effect of degree of saturation on compressibility was taken into account when fitting the results of the unconfined drying tests (obtaining $\chi=0.1372$ and $\omega=8.0$ ). As reported by Cotecchia et al. [5], these tests have been also used to calibrate the retention behaviour of the material, which has been modelled using the equation proposed by van Genuchten [20].

Unsaturated hydraulic conductivities of the Pisciolo clay have not been measured, so a model similar to the one proposed by van Genuchten [20] has been used to estimate the hydraulic conductivity function. On the other hand, the saturated hydraulic conductivity has been defined according to the in situ permeability measurements reported by Cotecchia et al. [5] $\left(\mathrm{k}_{\mathrm{in} \text { situ }}>10^{-9}\right.$ $\mathrm{m} / \mathrm{s}$ at depths lower than $30 \mathrm{~m}$ ).

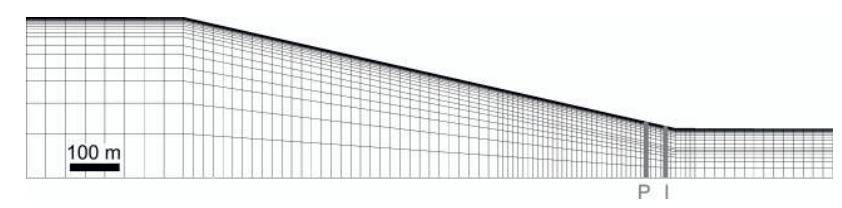

Figure 4. Finite element mesh used for the fully coupled hydromechanical analysis of the Pisciolo slope (modelled section in Fig. 1) $[3,4]$.

The numerical simulation has been conducted with reference to a longitudinal section representative of the most active portion of the slope (see Fig. 1). The finite element mesh (Fig. 4) was generated using isoparametric, quadrilateral, 8-noded elements, with two displacement degrees of freedom (DOF) on each node and pore water pressure DOF only on corner nodes.

The lateral boundaries of the finite element model have been horizontally constrained, while the bottom boundary has been fully fixed. As for the hydraulic boundary conditions, both lateral and bottom boundaries have been assumed as impervious, while net rainfalls have been applied on the top boundary of the mesh, using a dual hydraulic boundary condition $[15,21]$, which is capable of changing automatically from a prescribed flow to a prescribed pore water pressure boundary condition. This boundary condition makes it possible to account for run off, as rainfall infiltration stops when the pore pressures at the boundary nodes approach zero $[15,21]$.

Net rainfalls (Fig. 5) were calculated as the difference between gross rainfalls and evapo-transpiration fluxes, the latter estimated by means of the FAO PenmanMonteith method [22] according to temperature measurements only. Both gross rainfalls and temperatures have been measured at a weather station located in the town of Melfi (Italy), few kilometres away from the Pisciolo slope.

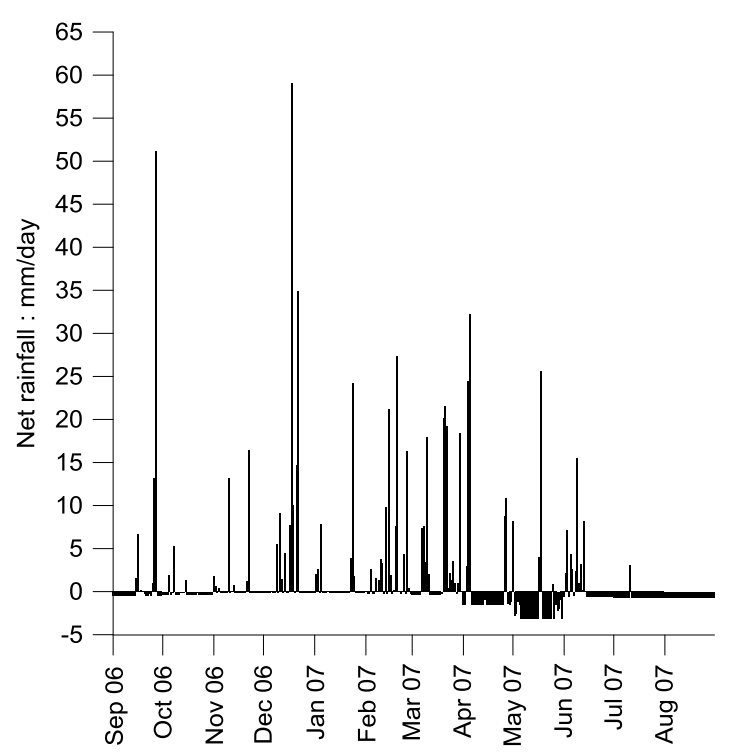

Figure 5. Net rainfalls used as boundary condition for the fully coupled hydro-mechanical analysis of the Pisciolo slope (Fig. 4) $[3,4]$.

The numerical model is able to reproduce seasonal pore pressure variations similar to those observed in situ (Fig. 6). These seasonal changes of the pore pressures induce the propagation of a shear band within the slope and the consequent formation of a landslide body that has geometrical features similar to those characterising the first-time failures observed within the Pisciolo slope (Fig. 7) [3,4].

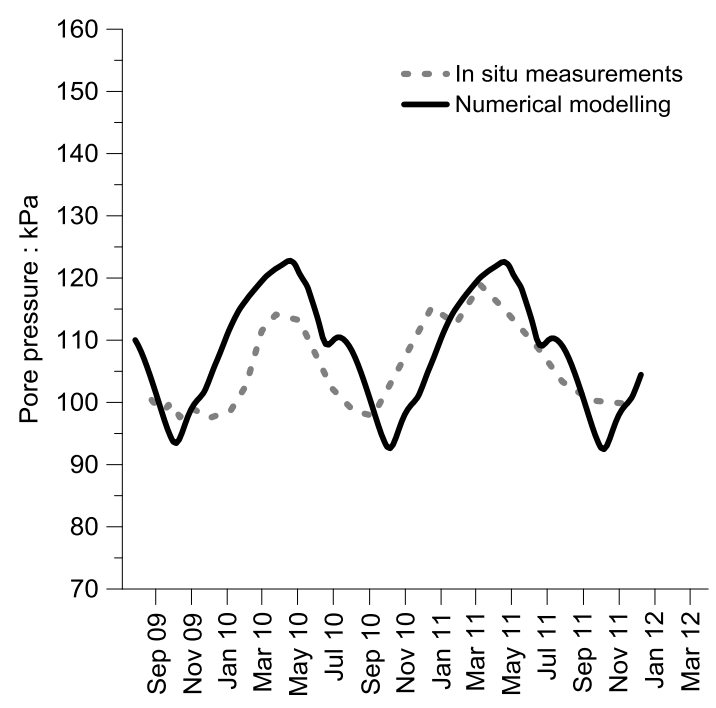

Figure 6. Comparison between numerical results (Fig. 4) and in situ measurements (Fig. 2) with reference to the pore pressures measured at the piezometer P located at $15 \mathrm{~m}$ depth (Fig. 1) [3]. 


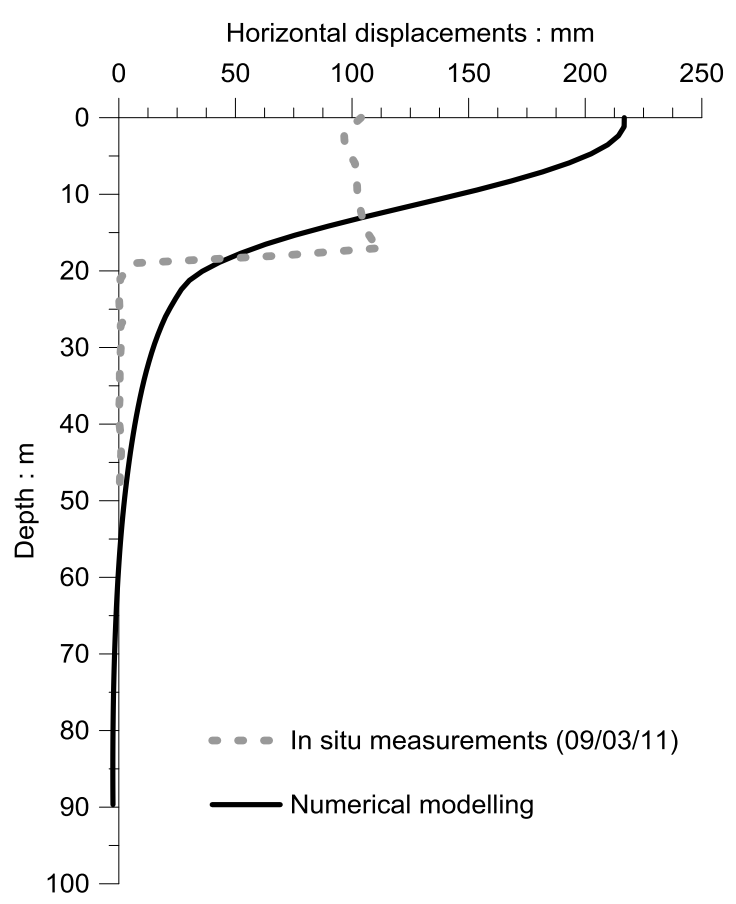

Figure 7. Comparison between numerical results (Fig. 4) and in situ measurements (Fig. 2) with reference to the inclinometer I (Fig. 1) [3].

\section{Conclusions}

The paper briefly introduces the Pisciolo case study [5], which is representative of the deep and slow landslide processes frequently observed in the Southern Apennines (Italy) [1-2]. A fully coupled hydro-mechanical finite element analysis confirmed that cumulated rainfall infiltration is the main factor triggering the instabilities. The numerical modelling was conducted with a constitutive model that is capable of simulating both saturated and unsaturated soil behaviour [16, 19], combined with a boundary condition able to simulate the effects of the slope-atmosphere interaction [15, 21]. In particular, the results of the numerical simulation prove that the soil-vegetation-atmosphere interaction is responsible for the formation of shear bands within the slope $[3,4]$.

\section{Acknowledgements}

Special thanks go to the Apulian Aqueduct Spa, that funded the research activities and provided precious information regarding the case study. The authors would also like to express their gratitude to researches and technicians of Technical University of Bari, CNR-IRPI of Bari and Imperial College London that supported the research project.

\section{References}

1. F. Cotecchia, C. Vitone, F. Santaloia, G. Pedone, O. Bottiglieri, Land. 12, 5, 877-893 (2015)

2. F. Cotecchia, F. Santaloia, P. Lollino, C. Vitone, G. Pedone, O. Bottiglieri, Eur. J. Environ. Civ. Eng. DOI: $10.1080 / 19648189.2014 .968744$ (2014)

3. G. Pedone, A. Tsiampousi, F. Cotecchia, L. Zdravkovic, First-time failures in clay slopes triggered by soil-vegetation-atmosphere interaction: numerical modelling of a case study in Southern Italy, in prep.

4. G. Pedone, Interpretation of slow and deep landslides triggered by slope-atmosphere interaction in slopes formed of fissured clayey turbidites $(\mathrm{PhD}$ thesis, Technical University of Bari, 2014)

5. F. Cotecchia, G. Pedone, O. Bottiglieri, F. Santaloia, C. Vitone, It. Geotech. J. 1, 34-61 (2014)

6. D. M. Cruden \& D. J. Varnes, Landslides: investigation and mitigation, special report 247, 3675 (1996)

7. J. N. Hutchinson, Proc. 5th Int. Symp. Land., Lausanne 1, 3-35 (1988)

8. G. Pedone, F. Cotecchia, O. Bottiglieri, J. Vaunat, Hydraulic characterisation of a fissured clay, in prep.

9. C. Vitone \& F. Cotecchia, Géotech. 61, 12, 1003$1018(2011)$

10. C. Vitone, F. Cotecchia, G. Viggiani, S. A. Hall, Int. J. Num. An. Meth. Geomech 37, 1510-1534 (2013)

11. C. Vitone, F. Cotecchia, G. Viggiani, S. A. Hall, Ac. Geotech. 8, 247-263 (2013)

12. F. A. M. Marinho \& O. M. Oliveira, Geotech. Test. J. 29, 3, 250-258 (2006)

13. A. M. Ridley \& J. B. Burland, Géotech. 43, 2, 321324 (1993)

14. D. M. Potts \& L. Zdravkovic, Finite element analysis in geotechnical engineering: theory (London, Thomas Telford, 1999)

15. P. G. Smith, Numerical analysis of infiltration into partially saturated slopes $(\mathrm{PhD}$ thesis, Imperial College London, 2003)

16. A. Tsiampousi, L. Zdravkovic, D. M. Potts, Comp. Geotech. 45, 2, 156-166 (2013)

17. E. E. Alonso, A. Gens, A. Josa, Géotech. 40, 3, $405-$ 430 (1990)

18. R. Lagioia, A. Puzrin, D. M. Potts, Comp. Geotech. 19, 3, 171-191 (1996)

19. A. Tsiampousi, L. Zdravkovic, D. M. Potts, Géotech. 63, 2, 155-164 (2013)

20. M. T. van Genuchten, Soil Scie. Soc. Amer. J. 44, 892-898 (1980)

21. P. G. Smith, D. M. Potts, T. I. Addenbrooke, Proc. 1st Eur. Conf. Unsat. Soils, 773-778 (2008)

22. R. G. Allen, L. S. Pereira, D. Raes, M. Smith, FAO Irr. Dran. Pap. 56 (1998) 